\title{
Wear characteristics of copper-based surface-level microcomposites and nanocomposites prepared by friction stir processing
}

\author{
S. CARTIGUEYEN ${ }^{*}$, K. MAHADEVAN \\ Department of Mechanical Engineering, Pondicherry Engineering College, Pondicherry 605014, India \\ Received: 30 July 2015 / Revised: 13 November 2015 / Accepted: 21 December 2015 \\ (C) The author(s) 2016. This article is published with open access at Springerlink.com
}

\begin{abstract}
In this study, microsized and nanosized silicon carbide particles (SiCps) were successfully incorporated into commercial pure copper to form a surface metal matrix composite by friction stir processing (FSP) at low-heat-input conditions. A cluster of blind holes on a copper plate was used as particle deposition technique during the fabrication of the composite. Pin-on-disc testing was performed under dry sliding conditions to determine the wear characteristics of prepared composite surfaces. The homogeneity of particle distribution both inside the copper matrix and in the wear scar was determined via microstructural observations. It was observed that both microsized and nanosized SiCps were well distributed and homogenous in a stir zone; particles observed were without defects, and good bonding was observed between SiCps and the copper matrix. Comparisons between $\mathrm{Cu} / \mathrm{SiCp}$ composite layers and friction stir processed (FSPed) $\mathrm{Cu}$ and as-received $\mathrm{Cu}$ showed that $\mathrm{Cu} / \mathrm{SiCp}$ nanocomposite layers exhibited superior microhardness and dry sliding wear characteristics.
\end{abstract}

Keywords: friction stir processing; surface engineering; surface metal matrix composites; microstructure; hardness; wear characteristics

\section{Introduction}

Pure copper and its alloys are attracting considerable interest worldwide because of their high thermal/ electrical conductivity, high plasticity, high formability, and good corrosion resistance. However, their poor wear resistance causes some limitations for applications [1]. In many engineering applications, surface properties are considered more important than bulk properties when deciding the lifetime of components. Hence, it is of significant interest to optimize the surface of components by reinforcing them with ceramic particles while leaving the bulk properties of the inner matrix intact. Modification of the surface layer using reinforced ceramic particles leads to the production of a surface metal matrix composite (SMMC) [2]; SMMCs are novel materials with superior

* Corresponding author: S. CARTIGUEYEN.

E-mail: scartigueyen@rediffmail.com mechanical and tribological properties when compared with metal matrix composites (MMCs) [3, 4]. Although several techniques are available to fabricate surface composites, friction stir processing (FSP) is a simple, green, and low-energy-consumption method based on the principles of friction stir welding to prepare surface-level composites with superior properties. FSP is a one-step thermomechanical solid-phase process that results in a dense solid without porosity, an absence of interfacial reactions (i.e., no detrimental phases), and a strong bonding between reinforcements and matrix material. SMMCs are one of the novel applications of FSP [5]. Asadi et al. [6] employed FSP to develop a composite layer on the surface of an as-cast AZ91 magnesium alloy using $5 \mu \mathrm{m}$ and $30 \mathrm{~nm}$ $\mathrm{SiC}$ particles. The effect of nanosized silicon carbide particles (SiCps) on the grain size and hardness of the composite layer was found to be more impressive than that of microsized particles. The second FSP 
pass further enhanced the distribution of SiCps and increased the hardness of the composite layer. Similarly, Dolatkhah et al. [7] fabricated MMCs on the surface of 5052 aluminum sheets using $5 \mu \mathrm{m}$ and $50 \mathrm{~nm}$ SiCps via FSP. Results show that the change of tool rotational direction between FSP passes, increase in FSP passes, and decrease of SiCp size enhance hardness and wear properties.

Copper-based MMCs reinforced with ceramics have been gaining much attention owing to their good mechanical, thermal, and tribological properties [8]. Barmouz et al. [9] produced $\mathrm{Cu} / \mathrm{SiC}$ surface composites using micron-sized SiCps via FSP using different process parameters to enhance the surface properties of the composites. Higher traverse speeds resulted in poorer dispersion of $\mathrm{SiCps}$ and consequently reduced the microhardness values of MMC layers. It was found that on the addition of SiCps, wear resistance and friction coefficients were improved. Barmouz et al. [10] also developed $\mathrm{Cu} / \mathrm{SiCp}$ surface composites via FSP with microsized and nanosized SiCps using the groove method for SiCp deposition. The size of SiCps considerably influenced the grain size and wear rate of the $\mathrm{Cu} / \mathrm{SiCp}$ surface composite. Nanosized SiCps yielded finer grains and lower wear rates compared to microsized SiCps. Multiple FSP passes enhanced the distribution of SiCps in the Cu matrix.

The agglomeration of reinforcement particles during FSP deteriorates the microstructure and mechanical properties of surface composites [11,12]. During composite fabrication by FSP, the reinforced particle deposition technique plays a vital role in obtaining agglomeration-free composites, which influence the final surface performance of the final composite [13]. Recently, Akramifard et al. [14] investigated the effectiveness of FSP where net holes are used in the particle deposition technique rather than the more conventional groove method for the successful fabrication of $\mathrm{Cu} / \mathrm{SiCp}$ surface composites with enhanced mechanical properties. Similarly, Sabbaghian et al. [15] developed a $\mathrm{Cu} / \mathrm{TiCp}$ surface composite using a set of fine holes for TiCps on a $\mathrm{Cu}$ sheet and investigated the effect of TiCps on the mechanical properties and microstructure. However, there is still a lack of information regarding the effect of particle size (microsized and nanosized) and a set of blind holes as the particle deposition technique on surface-level composites by
FSP. To date, there has rarely been a successful research on the effect of particle size and a set of blind holes as the particle deposition technique on the microstructure, particle distribution, microhardness, and wear characteristics of copper-based surface composites through FSP at adequate heat-input conditions. The present study mainly aims to describe the wear properties of copper-based microcomposites and nanocomposites prepared by FSP using a set of blind holes as the particle ( $\mathrm{SiCp}$ ) deposition technique. These wear properties are then compared with those of friction stir processed (FSPed) $\mathrm{Cu}$ and as-received $\mathrm{Cu}$.

\section{Experimental methods}

In this study, commercially pure $(99.98 \%)$ copper rolled plates of $150 \mathrm{~mm} \times 50 \mathrm{~mm} \times 6 \mathrm{~mm}$ were used as the base material. Commercial microsized $(\sim 12 \mu \mathrm{m})$ and nanosized $(\sim 50 \mathrm{~nm})$ SiCps were selected as reinforcement materials because of their good reinforcement properties and availability. A scanning electron microscopy (SEM) image of as-received microsized and nanosized SiCps is shown in Fig. 1. In FSP apparatus, the pin is the most important part; it plays a crucial role in the flow and mixing of materials. The use of a pin with a threaded profile enhances the flow and distribution of reinforcement particles in a matrix [6]. In this study, a reusable FSP tool was made of H13 steel with a hardness of $58 \mathrm{HRC}$. The pin had a straight cylindrical profile, $18 \mathrm{~mm}$ shoulder diameter, $3 \mathrm{~mm}$ probe length, and $6 \mathrm{~mm}$ diameter. The manufactured tool and its geometry are shown in Fig. 2(a). A cluster of blind holes with a diameter of $2 \mathrm{~mm}$ and depth of $3 \mathrm{~mm}$ was used for applying SiCps, as shown in Fig. 2(b), to obtain agglomeration-free surface composites. Two K-type thermocouples (1.6 mm diameter/ \pm 1.1 accuracy) were used to measure the peak temperature variation below the FSP tool shoulder. Thermocouples were inserted in blind holes drilled from the bottom of the $\mathrm{Cu}$ plate near the perimeter of the FSP tool shoulder and orthogonal to the path of the tool. Note that the thermocouples were inserted close to the surface of the plate, i.e., $0.15 \mathrm{~mm}$ from the top, considering the plunge depth of the tool $(0.1 \mathrm{~mm})$. Figure 2(c) schematically shows the locations of the thermocouples (TC1 and TC2) inserted at the advancing side (AS) and retreating side (RS) prior to FSP runs. 

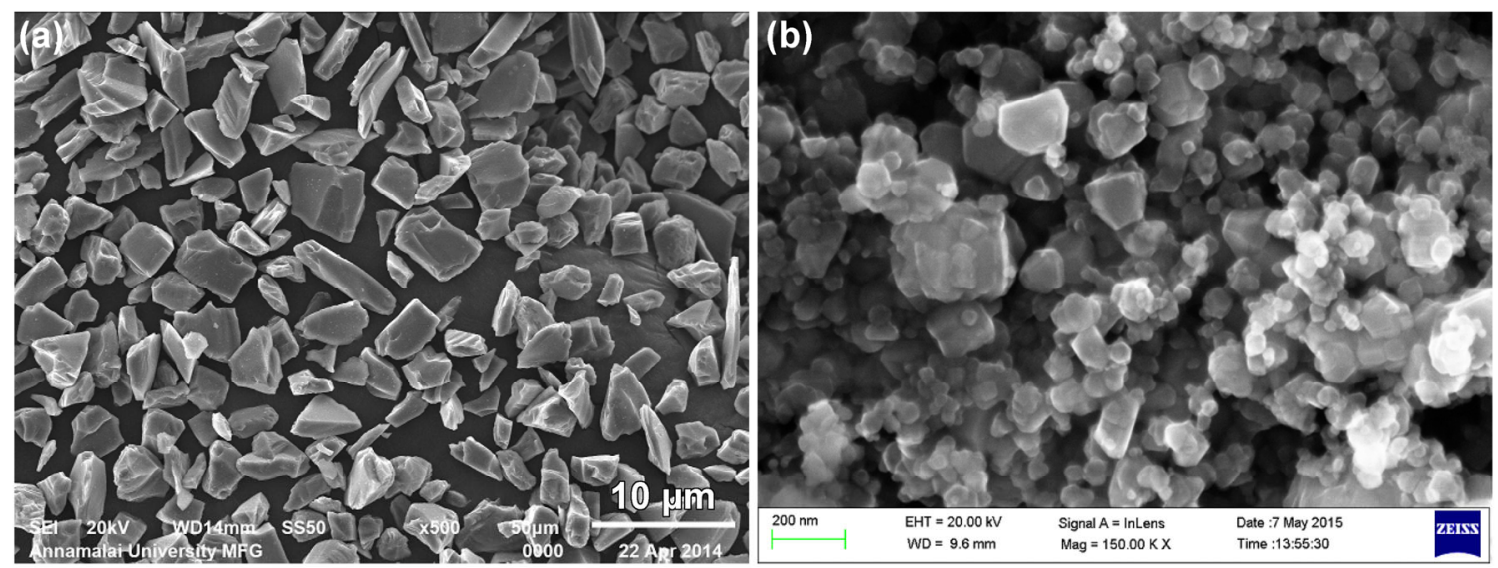

Fig. 1 (a) SEM image of micro-sized SiCp and (b) FESEM image of nano-sized SiCp.
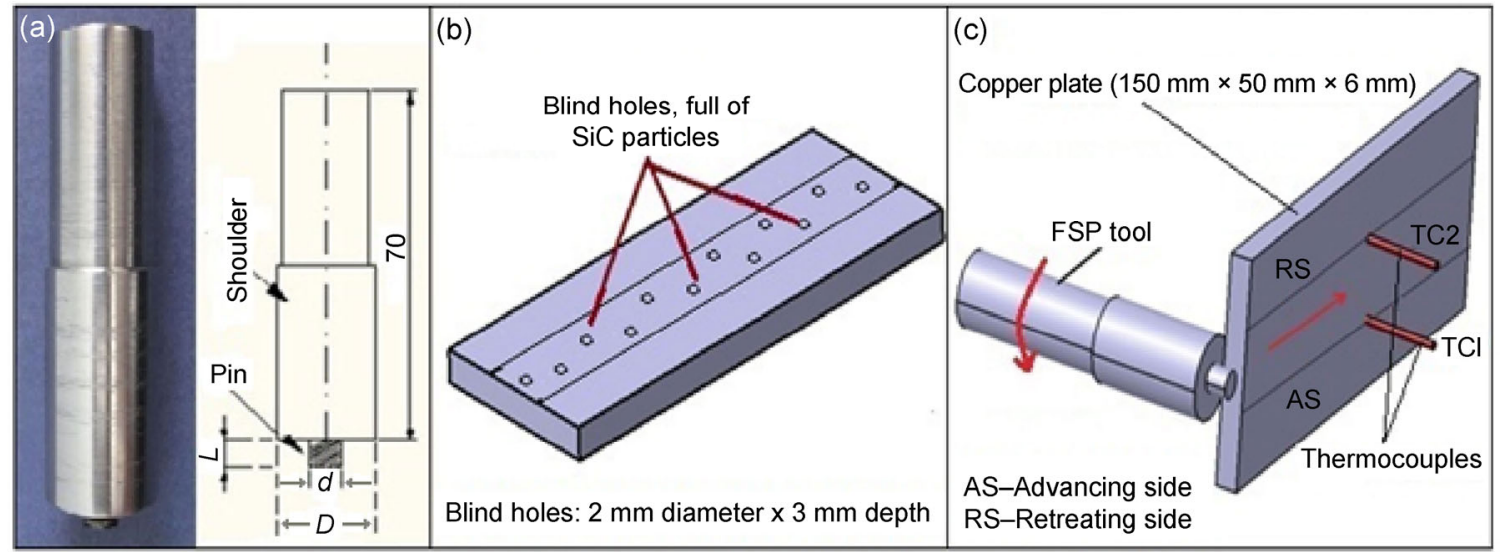

Fig. 2 (a) FSP tool \& its geometry ( $D$ — shoulder diameter, $d$ — pin diameter, $L$ — pin length); (b) design of blind holes ( $2 \mathrm{~mm}$ diameter and $3 \mathrm{~mm}$ depth) on $\mathrm{Cu}$ plate; (c) thermocouple locations.

At the start of FSP, blind holes were covered with an FSP tool without the pin; this prevented SiCps from being displaced from the blind holes during processing. The tool with the pin was then penetrated into the plate until the shoulder of the tool was $0.1 \mathrm{~mm}$ below the plate surface, achieving effective contact for frictional heating to obtain good formation in the processed zone. Single-pass FSP experiments were performed in a conventional vertical milling machine (3 HP and 2,000 rpm ratings). The microcomposite and nanocomposite samples processed by FSP at a constant speed of $500 \mathrm{rpm}$, processing speed of $50 \mathrm{~mm} / \mathrm{min}$, tool tilt angle of $1^{\circ}$, and axial force of $10 \mathrm{KN}$, which resulted in a relatively higher hardness with an effective particle distribution of SiCps, were selected for wear testing and compared with plain FSPed $\mathrm{Cu}$ processed under the same conditions and as-received
$\mathrm{Cu}$. Table 1 shows the sample categorization followed in this study. The distribution of dispersed SiCps was observed by optical microscopy (OM), SEM, and field emission scanning electron microscopy (FESEM). The microhardness profile of the stir zone (SZ) was determined across the cross-section of the samples with a constant load of $0.25 \mathrm{kgf}$ and dwelling period of $15 \mathrm{~s}$. Wear testing was conducted using pin-on-disc

Table 1 Sample categorization.

\begin{tabular}{cc}
\hline Sample & Condition of specimen sample \\
\hline S1 & As-received pure copper \\
S2 & Plain FSPed copper at $500 \mathrm{rpm}$ and $50 \mathrm{~mm} / \mathrm{min}$ \\
& Micro-sized $\mathrm{Cu} / \mathrm{SiC}$ composite at $500 \mathrm{rpm}$ and \\
S3 & $50 \mathrm{~mm} / \mathrm{min}$ \\
& Nano-sized $\mathrm{Cu} / \mathrm{SiC}$ composite at $500 \mathrm{rpm}$ and \\
S4 & $50 \mathrm{~mm} / \mathrm{min}$ \\
\hline
\end{tabular}


apparatus as per ASTM G99-04 standard. The wear tests were performed under dry sliding conditions with a constant load of $30 \mathrm{~N}$, sliding distance of $500 \mathrm{~m}$, and sliding speed of $1.0 \mathrm{~m} / \mathrm{s}$. Thereafter, the worn surfaces of the samples were investigated by SEM.

\section{Results and discussion}

\subsection{Macrostructure and temperature history during FSP}

The amount of heat generated during FSP is an important factor when producing a defect-free FSPed zone and very crucial in controlling the resulting microstructure and consequently the mechanical properties [16]. The thermocouple placement was intended to enable the assessment of peak temperature variation (heat-input variations) in both the AS and RS of the SZ (as in Fig. 2(c)). It was experimentally observed that peak temperatures were higher on the AS than RS in all three samples (FSPed $\mathrm{Cu}$, microcomposites, and nanocomposites) processed at $500 \mathrm{rpm}$ and $50 \mathrm{~mm} / \mathrm{min}$ [17]. Table 2 shows the defect-free macrostructure and peak temperature variations for FSPed $\mathrm{Cu}$ and fabrication of surface-level microcomposites and nanocomposites by FSP. The peak temperature rise varies between $328^{\circ} \mathrm{C}$ and $358^{\circ} \mathrm{C}$, indicating that low-heat-input conditions occurred during FSP, where the grain refinement phenomenon was dominant, and that no phase transformation occurred during FSP [18]. It can be observed that the peak temperature for microcomposites is slightly higher than that for nanocomposites; this is because of the presence of microsized SiCps, which resist the material flow more than nanosized SiCps during FSP.

\subsection{Microstructural characterization}

The X-ray diffraction (XRD) patterns of microsized and nanosized $\mathrm{SiCp}$ reinforced surface composites by FSP are shown in Fig. 3. The peaks of SiCps in both the microcomposites and nanocomposites appear weak because the volume fraction of SiCps is smaller than that of $\mathrm{Cu}$ [19]. Figures 3(a) and (b) show that there is no evidence of a new phase (intermetallic compounds). This can be attributed to adequate heat generation during FSP. Moreover, some SiC reflections disappeared because of the good dispersion and size reduction of SiCps. The microscopic images of as-received $\mathrm{Cu}$, the SZ section of the FSPed specimen, and surface composites are shown in Figs. 4(a)-4(d). The mean grain size in as-received Cu used in this study is $30 \mu \mathrm{m}$. It was observed from the OM images (Figs. 4(a) and (b)) of as-received $\mathrm{Cu}$ and FSPed $\mathrm{Cu}$ that the grain size was significantly reduced to $7 \mu \mathrm{m}$ because of the low-heat-input conditions during FSP [17]. As shown in Fig. 4(c), performing FSP leads to the fabrication of a dynamically recrystallized ultra-fine-grained structure (grain size $\sim 2 \mu \mathrm{m}$ ) with uniform distribution of microsized SiCps in the surface composite layer. Figure 4(d) shows the FESEM image of the nanocomposite layer with uniform dispersion of nanosized SiCps using a set of blind holes as the particle ( $\mathrm{SiCp}$ ) deposition technique during FSP. Figure 4(e) is a magnified version of Fig. 4(d). Results of energy-dispersive X-ray analysis are shown in Fig. 5. This shows the

Table 2 Macrostructure and peak temperature variation during FSP of samples.

\begin{tabular}{|c|c|c|c|}
\hline \multirow{2}{*}{ Sample } & \multirow{2}{*}{ Macrostructure } & \multicolumn{2}{|c|}{ Peak temperature $\left({ }^{\circ} \mathrm{C}\right)$} \\
\hline & & Retreating side (TC2) & Advancing side (TC1) \\
\hline S2-FSPed Cu & & 315 & 328 \\
\hline S3-Microcomposite & & 342 & 358 \\
\hline S4-Nanocomposite & & 338 & 352 \\
\hline
\end{tabular}



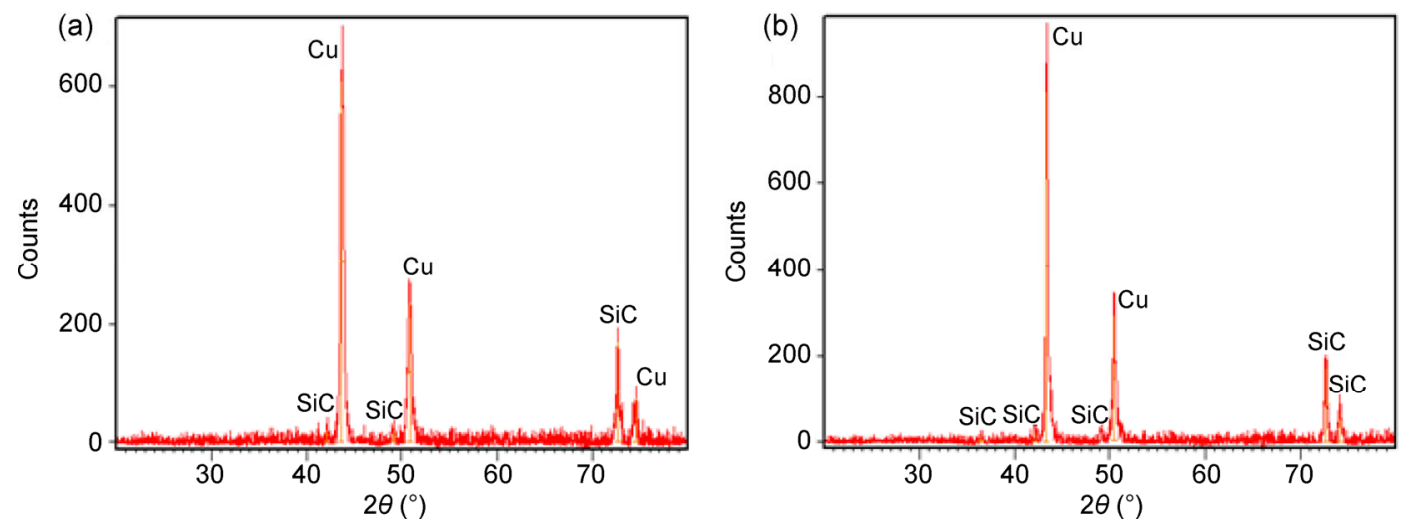

Fig. 3 X-ray diffraction pattern of $\mathrm{Cu} / \mathrm{SiCp}$ (a) micro-composite and (b) nano-composite.
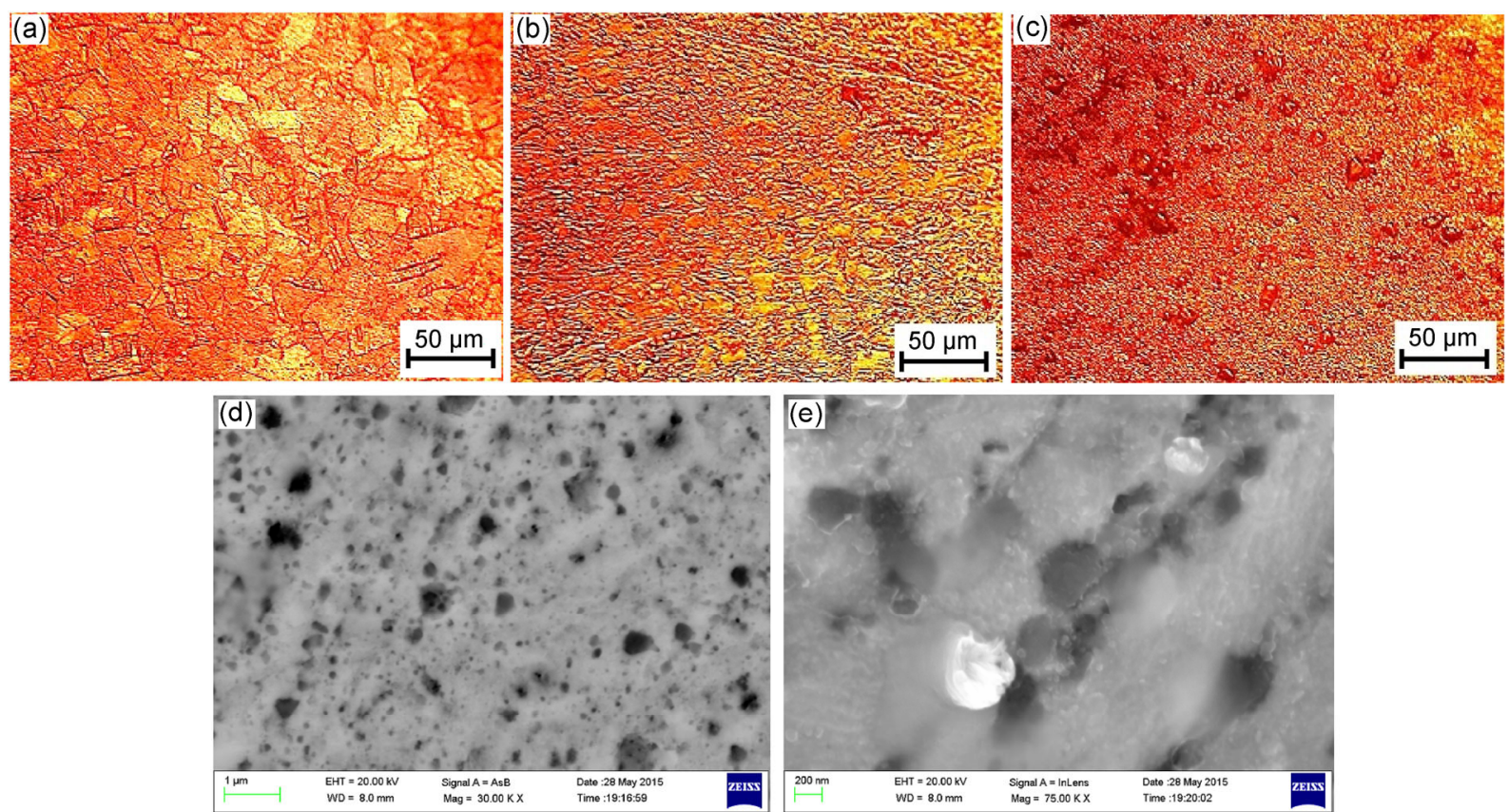

Fig. 4 Optical micrographs of (a) as-received $\mathrm{Cu}$, (b) FSPed $\mathrm{Cu}$, (c) micro-composite, and FESEM image of (d) nano-composite and (e) higher magnification of (d).

presence of elements such as $\mathrm{Si}, \mathrm{C}$, and $\mathrm{Cu}$ in a nanocomposite layer with quantitative results. The percentage of $\mathrm{SiCps}$ in the prepared surface composites was found to be $1.75 \%$ by volume.

\subsection{Microhardness}

Table 3 shows the average grain size of as-received $\mathrm{Cu}$ and the SZ of the specimens produced by FSP without reinforcement particles and with microsized and nanosized SiCp reinforced composites. The microhardness of the processed $\mathrm{Cu}$ plates is normally influenced by heat generation and subsequent grain refinement [17]. According to the Hall-Petch relationship, hardness increases as grain size decreases. The grain size in the SZ of the FSPed Cu sample decreases to $7 \mu \mathrm{m}$ because of adequate input conditions (500 rpm and $50 \mathrm{~mm} / \mathrm{min}$ ), which increase the average microhardness in the SZ to $103 \mathrm{HV}$ from the average hardness of pure $\mathrm{Cu}(97 \mathrm{HV})$.

The fine-grain refinement in the microcomposites and nanocomposites produced by FSP is related to the presence of SiCps that were uniformly distributed among the grain boundaries of a matrix and restricted the grain growth during solidification. The average hardness of the surface-level composites in the SZ was found to be $168 \mathrm{HV}$ with the addition of microsized 


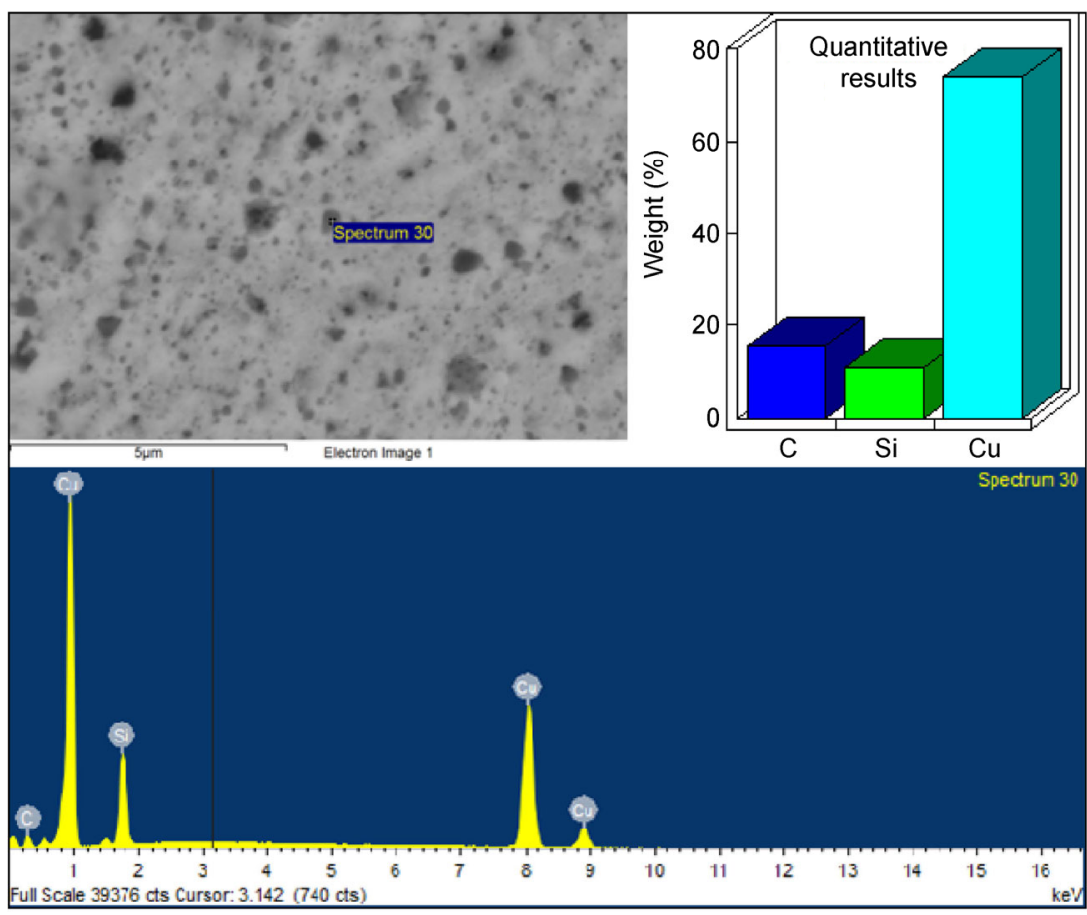

Fig. 5 EDAX report with quantitative results of nano-composite layer.

Table 3 Wear characteristics of various samples.

\begin{tabular}{lccccc}
\hline \multicolumn{1}{c}{ Sample } & $\begin{array}{c}\text { Grain size } \\
(\sim \mu \mathrm{m})\end{array}$ & $\begin{array}{c}\text { Co-efficient of } \\
\text { friction }(\mu)\end{array}$ & $\begin{array}{c}\text { Wear rate } \\
\left(10^{-5} \mathrm{~g} / \mathrm{cm}\right)\end{array}$ & $\begin{array}{c}\text { Wear resistance } \\
\left(10^{5} \mathrm{~cm} / \mathrm{g}\right)\end{array}$ & $\begin{array}{c}\text { Wear resistance } \\
\left(10^{5} \mathrm{~m} / \mathrm{Kg}\right)\end{array}$ \\
\hline S1-As received $\mathrm{Cu}$ & 30 & 0.314 & 1.7993 & 0.55577 & 0.055577 \\
S2-FSPed Cu & 7 & 0.332 & 0.9965 & 1.00351 & 0.100351 \\
S3-Microcomposite & 2 & 0.598 & 0.5998 & 1.66722 & 0.166722 \\
S4-Nanocomposite & $<2$ & 0.643 & 0.3999 & 2.50063 & 0.250063 \\
\hline
\end{tabular}

SiCps and $189 \mathrm{HV}$ with the addition of nanosized SiCps. The measured average microhardness of the nanocomposites was $\sim 95 \%$ higher than that of pure $\mathrm{Cu}$ and $\sim 13 \%$ higher than that of the microcomposites. Figure 6 shows the hardness variation of the FSPed sample and surface composites from as-received $\mathrm{Cu}$. The increase in hardness was attributed to the fine dispersion of SiCps and the fine grain size of the copper matrix (as revealed in Figs. 4(c) and 4(d)). Increasing hardness in the SZ during FSP with SiCp addition can be attributed to the following:

1. Hard phase dispersion of SiCps (Orowan strengthening mechanism).

2. Grain refinement in the SZ (Hall-Petch relationship).

3. Quench hardening (due to the variation in thermal reduction between $\mathrm{SiCps}$ and $\mathrm{Cu}$ matrix).

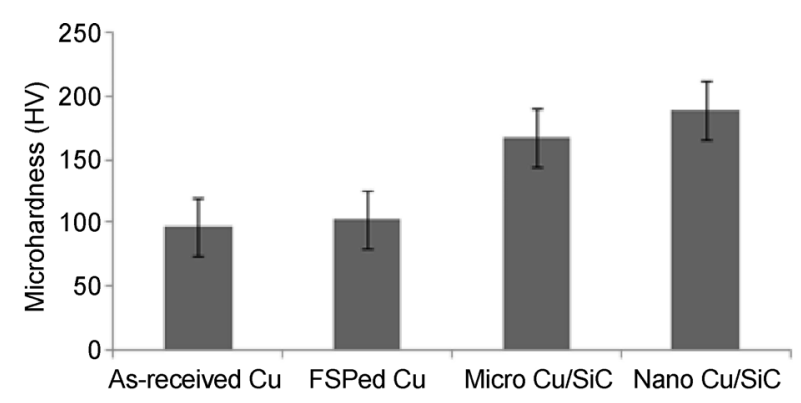

Fig. 6 Variation of microhardness in as-received $\mathrm{Cu}, \mathrm{FSPed} \mathrm{Cu}$ and $\mathrm{Cu} / \mathrm{SiC}$ composite samples.

4. Work hardening (caused by the strain misfit between elastic $\mathrm{SiCps}$ and plastic $\mathrm{Cu}$ ).

\subsection{Wear behavior}

Pin-on-disc wear testing was performed using flat pins (6 $\mathrm{mm}$ diameter) prepared from the composite 
samples. The pin was positioned perpendicular to flat EN31 steel plates with a hardness of 62 HRC. Dry sliding tests were performed as detailed in ASTM G99-04 using a constant load of $30 \mathrm{~N}$, sliding distance of $500 \mathrm{~m}$, and sliding speed of $1.0 \mathrm{~m} / \mathrm{s}$. In the pin-ondisc apparatus, the disc rotates, and the pin remains stationary. The rotation of the disc creates a sliding path where the pin has been in contact with the plate. The rpm was adjusted according to the preset linear sliding speed and the diameter of the wear track. To study the wear behavior of samples and the effect of reinforcement particles on wear resistance, the material removed from the samples was weighed using a precision electronic balance with $\pm 0.1 \mathrm{mg}$ accuracy. Wear rate was calculated using Eq. (1), which shows the relationship between weight loss and sliding distance of the samples:

$$
W_{\mathrm{r}}=\frac{\Delta w}{2 \pi r n t}
$$

where $W_{\mathrm{r}}$ is the wear rate in $\mathrm{g} / \mathrm{cm}, \Delta w$ is the difference in the weight of the specimen before and after wear testing in $\mathrm{g}, 2 \pi r$ is the sliding distance in $\mathrm{cm}, n$ is the speed in rpm, and $t$ is the time in minutes.
Table 3 shows the variation of the wear rate in $\mathrm{g} / \mathrm{cm}$ for as-received $\mathrm{Cu}$, FSPed $\mathrm{Cu}$, microsized, and nanosized composite layers produced by FSP at rotational and processing speeds of $500 \mathrm{rpm}$ and $50 \mathrm{~mm} / \mathrm{min}$, respectively. The changes in the wear rate can be attributed to the following reasons. (a) Plain FSP of the copper sample at low-heat-input conditions leads to a reduction in the grain size $(7 \mu \mathrm{m})$, which increases the hardness value (103 HV) of FSPed Cu [17]. This increase in hardness improves wear resistance to a greater extent than as-received $\mathrm{Cu}$. (b) Presence of microsized and nanosized SiCps enhanced the microhardness of the composite layers. The good dispersion of SiCps and the fine grain structure are the main reasons for this phenomenon, which improves the wear resistance of composites [20]. (c) Orowan strengthening mechanism was due to effective bonding and dispersion of ceramic particles with matrix material [21]. (d) Decreasing direct load contact between the $\mathrm{Cu} / \mathrm{SiCp}$ microcomposite and nanocomposite surfaces (pin) and the steel (disc) was because of load bearing component action of hard SiCps [9, 22].

Figure 7 shows the change in friction coefficients over time for a sliding distance of $500 \mathrm{~m}$ for different samples. The large changes in friction coefficients are
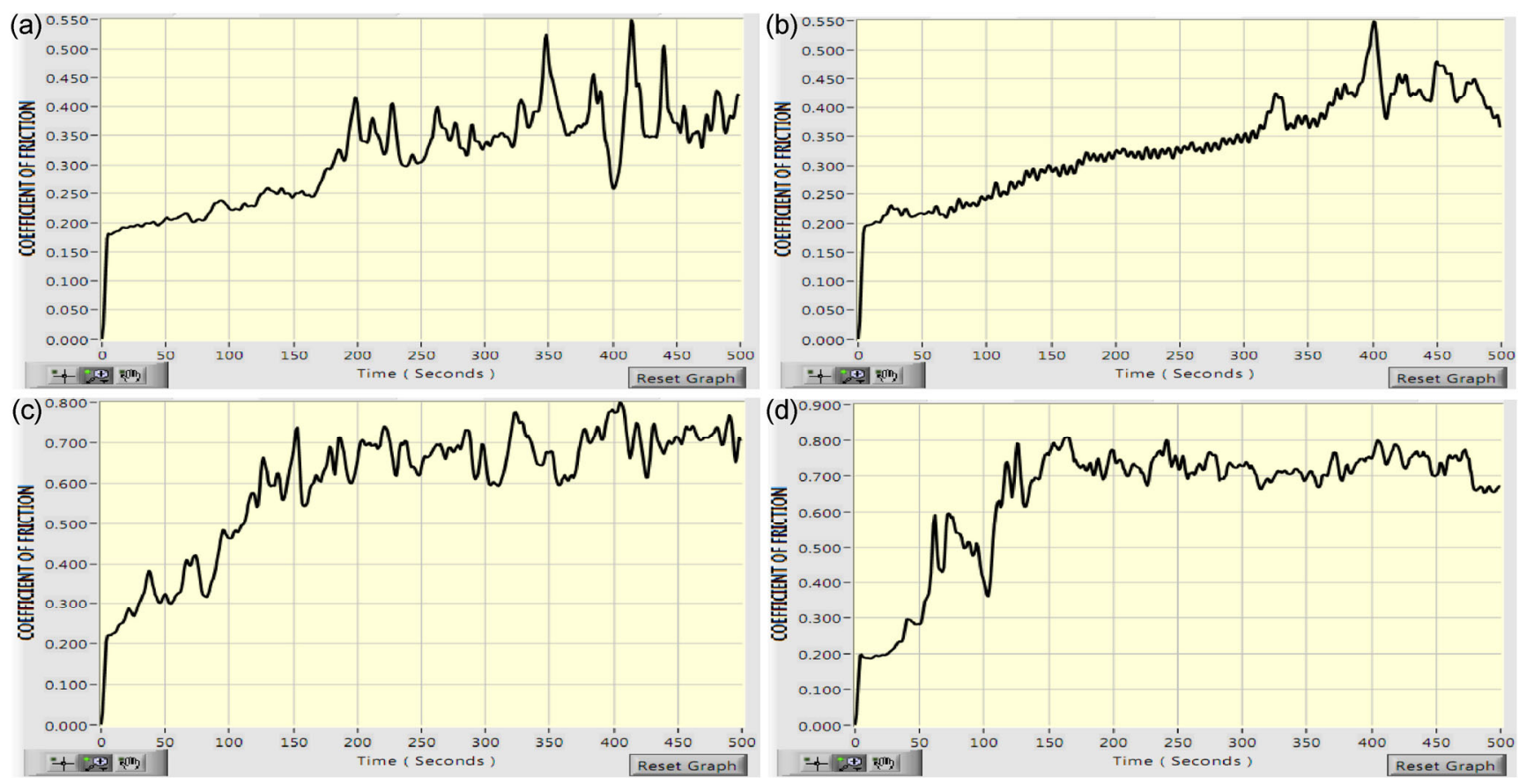

Fig. 7 Coefficient of friction with time for (a) as-received $\mathrm{Cu}$, (b) FSPed $\mathrm{Cu}$, (c) micro-composite and (d) nano-composite. 
caused by the periodical accumulation and elimination of wear debris in the wear scar and repeated banding structure in the tool-traveling direction [22-24]. The mean friction coefficients for as-received $\mathrm{Cu}$, FSPed $\mathrm{Cu}$, microsized composites, and nanosized composites were $0.314,0.332,0.598$, and 0.643, respectively. Results showed that FSP slightly increased the friction coefficient for FSPed $\mathrm{Cu}$ because of low-heat-input conditions where the grain refinement was dominant. It can be observed that the mean friction coefficient of $\mathrm{Cu} / \mathrm{SiCp}$ composites with microsized and nanosized SiCps was significantly higher than those of FSPed $\mathrm{Cu}$ and pure $\mathrm{Cu}$. This may be because of the presence of SiCps in the composites resulting in higher wear resistance against the sliding contact [14, 21, 22]. It was also found that the wear resistance (wear resistance $=$ $1 /$ wear rate) of the nanocomposites is much superior to microsized $\mathrm{SiCp}$ reinforced composites, FSPed $\mathrm{Cu}$, and as-received $\mathrm{Cu}$ (Table 3). This is because of the relatively higher microhardness value $(189 \mathrm{HV})$ and the presence of relatively stronger bonding between the $\mathrm{Cu}$ matrix and nanosized SiCps, as depicted in Fig. 4(d).

For the nanocomposite layer, the presence of nanoparticles improves hardness and material strength against plastic deformation and reduces the adhesion between the wear disc and pin $[25,26]$. The nanocomposite has a lower weight loss than as-received $\mathrm{Cu}$, FSPed $\mathrm{Cu}$, and microcomposites. Low material hardness, such as that displayed by as-received $\mathrm{Cu}$ and FSPed $\mathrm{Cu}$, leads to an increase in wear volume and a reduction in wear resistance when load and sliding distance remain constant. This relationship is show in Eq. (2) [27]:

$$
W_{\mathrm{v}}=\frac{K L D}{H}
$$

where $W_{\mathrm{v}}$ is the wear volume, $K$ is the wear coefficient, $L$ is the load, $D$ is the sliding distance, and $H$ is the hardness. For the nanocomposite layer, the hardness of nanosized particles allows them to act as loadbearing components; this significantly reduces the contact area between the disc and soft copper matrix of the pin, thereby protecting it from deterioration and improving the wear resistance of the nanocomposite layer.

\subsection{Worn surface characteristics}

Figure 8 reveals the SEM images of worn surfaces of pure $\mathrm{Cu}$, FSPed $\mathrm{Cu}$, microsized, and nanosized composite specimens. Figures $8(\mathrm{a})$ and $8(\mathrm{~b})$ reveal deeply scratched grooves parallel to each other in the sliding direction for pure $\mathrm{Cu}$ and FSPed $\mathrm{Cu}$ where the adhesion dominates the sliding wear at the wear scar. However, a change in the wear mode was observed because of the presence of microsized and nanosized SiCps in the composite samples, which can be attributed to the homogeneous distribution of SiCps in the SZ as a result of FSP (Figs. 8(c) and 8(d)) when using a set of blind holes as the particle deposition technique. The debris particles shown in Figs. 8(c) and $8(\mathrm{~d})$ are related to the oxidization and removal of the $\mathrm{Cu}$ matrix and the segregation of SiCps from the MMC layer during wear testing. Abrasive wear can therefore be determined to be the dominant wear mechanism in the surface composite layers. As shown in Fig. 8(c), the microcomposite sample exhibits shallow abrasive grooves in the wear scar, but the nanocomposite sample exhibits a comparatively smooth wear scar and some shallow abrasive grooves (Fig. 8(d)) on the worn surface.

Heat generated because of friction increases the temperature at the wear surface; this leads to plastic deformation and dislocation at the inner surface layer of the composites. The increase in the temperature causes the formation of an oxide layer, and wear debris became embedded in the soft copper matrix, forming a mechanically mixed layer (MML) on the worn surface. There are two conditions for the formation of MML in worn surfaces: one is intense plastic flow of the surface material, and the other is the presence of second phases (SiCps) in the materials that are harder than the counter material (EN31 hard steel disc). Oxidation appears to have played an important role because oxide particles generated from the steel counter face surface appeared to stabilize the MML. It can be observed that the formation of the MML drastically reduces the wear rate in the prepared composites. However, the presence of coarse SiCps $(\mu \mathrm{m})$, which had a low integrity with the copper matrix (low heat input during FSP), caused the delamination of the MML in the microcomposite layer. The presence of 

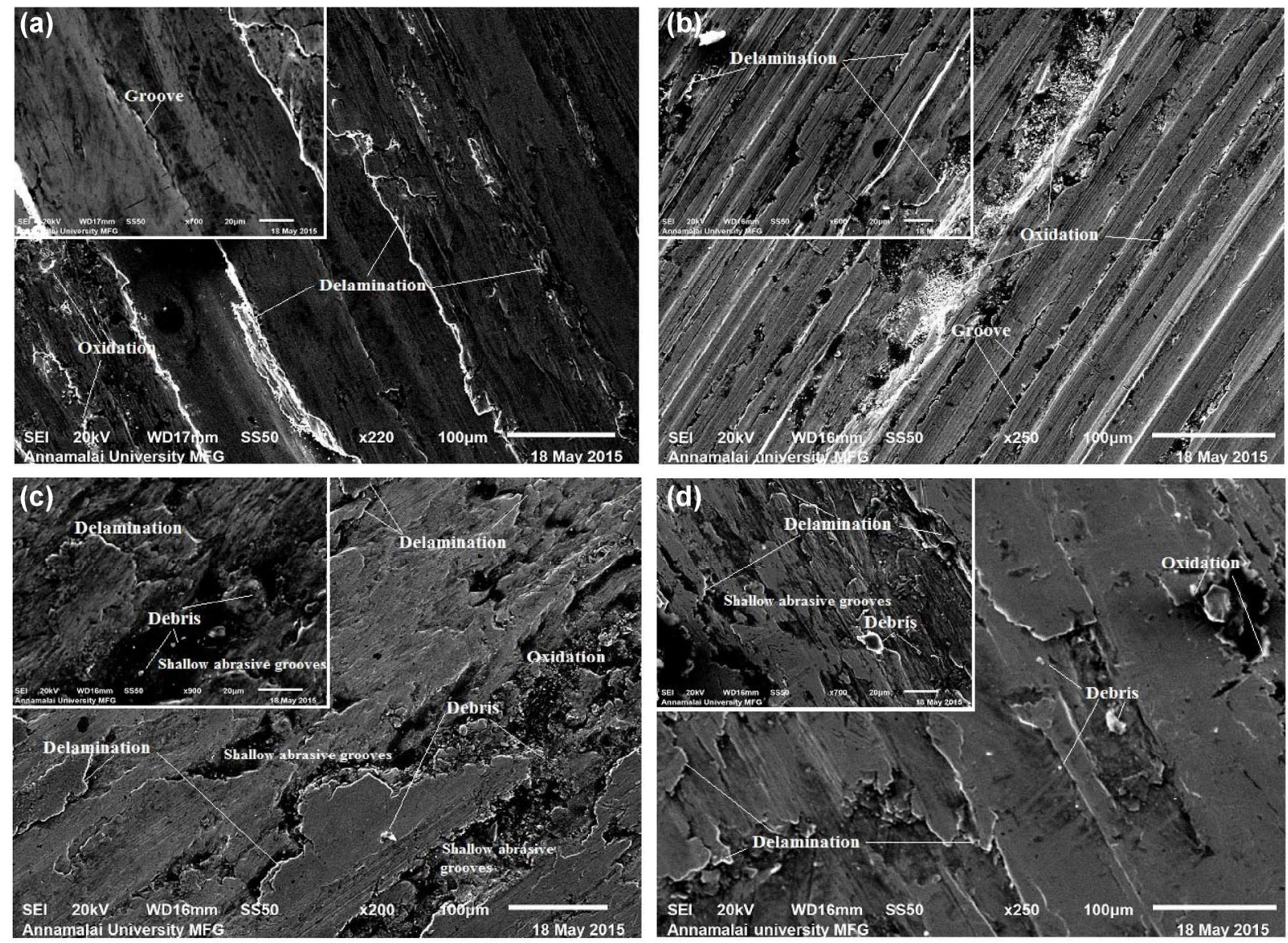

Fig. 8 SEM images of wear surface of (a) as-received $\mathrm{Cu}$, (b) FSPed Cu, (c) micro-composite and (d) nano-composite.

less debris in Fig. 8(d) compared with Fig. 8(c) is a sign of the superior wear resistance of $\mathrm{Cu} / \mathrm{SiCp}$ nanocomposite layer. The excellent wear resistance of the nanocomposite is mainly attributed to the following reasons: (a) the higher number of nanosized SiCps than microsized SiCps (although the volume percentage was the same for both microcomposites and nanocomposites) [10], (b) good bonding of nanosized SiCps with the Cu matrix [20], (c) the higher microhardness value (189 HV) due to nanosized SiCps, and (d) SiCps sustaining wearing loads and impeding direct load contact of the $\mathrm{Cu}$ matrix and the disc [22].

\section{Conclusions}

In this study, the dry sliding wear characteristics of prepared $\mathrm{Cu} / \mathrm{SiCp}$ surface-level microcomposite and nanocomposite layers prepared by FSP were investigated. The conclusions are summarized as follows:
- The microhardness of $\mathrm{Cu} / \mathrm{SiCp}$ microcomposites and nanocomposites are higher than those of FSPed and as-received $\mathrm{Cu}$ because of the grain refinement of a matrix and improved distribution of $12 \mu \mathrm{m}$ and $50 \mathrm{~nm}$ SiCps in the matrix. Nanocomposite layers show higher hardness up to $189 \mathrm{HV}$, which is $13 \%$, $84 \%$, and $95 \%$ higher than microcomposite, FSPed $\mathrm{Cu}$, and as-received $\mathrm{Cu}$, respectively.

- The reduction in the wear rate was greater for $\mathrm{Cu} /$ $\mathrm{SiCp}$ than FSPed $\mathrm{Cu}$ and as-received $\mathrm{Cu}$ because of the dispersion of SiCps as a hard ceramic phase in the $\mathrm{Cu}$ matrix. The nanocomposites exhibited superior wear resistance of $33 \%, 59 \%$, and $78 \%$ more than microcomposites, FSPed $\mathrm{Cu}$, and as-received $\mathrm{Cu}$, respectively.

- The friction coefficient of FSPed $\mathrm{Cu}$ was slightly higher than that of as-received $\mathrm{Cu}$ at low-heatinput conditions, and the friction coefficient of the surface composites was significantly higher than 
those of FSPed $\mathrm{Cu}$ and as-received $\mathrm{Cu}$. Reduction of SiCp size enhanced the wear characteristics of the prepared copper-based surface composites.

Open Access: The articles published in this journal are distributed under the terms of the Creative Commons Attribution 4.0 International License (http://creativecommons.org/licenses/by/4.0/), which permits unrestricted use, distribution, and reproduction in any medium, provided you give appropriate credit to the original author(s) and the source, provide a link to the Creative Commons license, and indicate if changes were made.

\section{References}

[1] Ziyuan S H, Deqing W. Surface dispersion hardening $\mathrm{Cu}$ matrix alloy. Appl Surf Sci 167: 107-112 (2000)

[2] Attia A N. Surface metal matrix composites. Materd Design 22: 451-457 (2001)

[3] Funatani K. Emerging technology in surface modification of light metals. Surf Coat Technol 133-134: 264-272 (2000)

[4] Shinoda T, Kawai M. Surface modification by novel friction thermomechanical process of aluminum alloy castings. Surf Coat Technol 160-170: 456-459 (2003)

[5] Mishra R S, Ma Z Y, Charit I. Friction stir processing: A novel technique for fabrication of surface composite. Mater Sci Eng A 341: 307-310 (2003)

[6] Asadi P, Besharati Givi M K, Abrinia K, Taherishargh M, Salekrostam R. Effects of $\mathrm{SiC}$ particle size and process parameters on the microstructure and hardness of AZ91/SiC composite layer fabricated by FSP. J MaterEng Perform 20(9): 1554-1562 (2011)

[7] Dolatkhah A, Golbabaei P, Besharati Givi M K, Molaiekiya F. Investigating effects of process parameters on microstructural and mechanical properties of A15052/SiC metal matrix composite fabricated via friction stir processing. Mater Design 37: 458-464 (2012)

[8] Romankov S, Hayasaka Y, Shchetinin J, Yoona M, Komarov $\mathrm{S}$ V. Fabrication of $\mathrm{Cu}-\mathrm{SiC}$ surface composite under ball collisions. Appld Surf Scie 257: 5032-5036 (2011)

[9] Barmouz M, Besharati Givi M K, Seyfi J. On the role of processing parameters in producing $\mathrm{Cu} / \mathrm{SiC}$ metal matrix composites via friction stir processing: Investigating microstructure, microhardness, wear and tensile behavior. Mater Charact 62: 108-117 (2011)
[10] Barmouz M, Asadi P, Besharati Givi M K, Taherishargh M. Investigation of mechanical properties of $\mathrm{Cu} / \mathrm{SiC}$ composite fabricated by FSP: Effect of SiC particles' size and volume fraction. Mater Sci Eng A 528: 1740-1749 (2011)

[11] Wang W, Shi Q, Liu P, Li H, Li T. A novel way to produce bulk $\mathrm{SiCp}$ reinforced aluminum metal matrix composites by friction stir processing. J Mater Process Technol 209: 2099-2103 (2009)

[12] Barmouz M, Besharati Givi M K. Fabrication of in situ $\mathrm{Cu} / \mathrm{SiC}$ composites using multi-pass FSP: Evaluation of microstructural, porosity, mechanical and electrical behavior. Compos Part A 42: 1445-1453 (2011)

[13] Miranda R M, Gandra J, Vilaça P. Surface modification by friction based processes. Licensee InTech, 2013.

[14] Akramifard H R, Shamanian M, Sabbaghian M, Esmailzadeh M. Microstructure and mechanical properties of $\mathrm{Cu} / \mathrm{SiC}$ metal matrix composite fabricated via friction stir processing. Mater Design 54: 838-844 (2014)

[15] Sabbaghiana M, Shamaniana M, Akramifard H R, Esmailzadeh M. Effect of friction stir processing on the microstructure and mechanical properties of $\mathrm{Cu}-\mathrm{TiC}$ composite. Ceram Int 40(8): 12969-12976 (2014)

[16] Khraisheh M K, Darras B M, Omar M A. Experimental thermal analysis of friction stir processing. Mater Sci Forum 539-543: 3801-3806 (2007)

[17] Cartigueyen S, Mahadevan K. Influence of rotational speed on the formation of friction stir processed zone in pure copper at low-heat input conditions. J Manuf Process 18: 124-130 (2015)

[18] Surekha K, Els-Botes A. Development of high strength, high conductivity copper by friction stir processing. Mater Design 32: 911-916 (2011)

[19] Schwarzenbach D. Crystallography. Switzerland: Institute of Crystallography, University of Lausanne,1996.

[20] Ramesh C S, Noor Ahmed R, Mujeebu M A, Abdullah M Z. Development and performance analysis of novel cast copperSiC-Gr hybrid composites. Mater Design 30: 1957-1965 (2009)

[21] Maxwell Rejil C, Dinaharan I, Vijay S J, Murugan N. Microstructure and sliding wear behavior of AA6360/(TiC + B4C) hybrid surface composite layer synthesized by friction stir processing on aluminum substrate. Mater Sci Eng A 552: 336-344 (2012)

[22] Mahmoud E R I, Takahash M, Shibayanagi T, Ikeuchi K. Wear characteristics of surface-hybrid-MMCs layer fabricated on aluminum plate by friction stir processing. Wear $\mathbf{2 6 8}$ : 1111-1121(2010) 
[23] Mishra R S, Ma Z Y. Friction stir welding and processing. Mater Sci Eng: R 50: 1-78 (2005)

[24] Ma Z Y. Friction stir processing technology. Metall Mater Trans A 39: 642-658 (2008)

[25] Miyajima T, Iwai Y. Effects of reinforcements on sliding wear behavior of aluminum matrix composites. Wear $\mathbf{2 5 5}$ : 606-616 (2003)

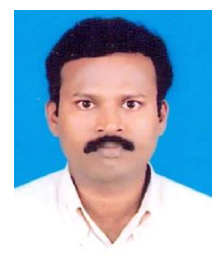

Srinivasan CARTIGUEYEN. He received his B.Tech. degree in mechanical engineering and M.Tech. degree in energy technology from Pondicherry University, Puducherry, India in 1993 and 1996 respectively. His current position is a selection grade lecturer in the Department
[26] Sathiskumar R, Murugan N, Dinaharan I, Vijay S J. Prediction of mechanical and wear properties of copper surface composites fabricated using friction stir processing. Mater Design 55: 224-234 (2014)

[27] Stachowiak G. Wear-Materials, Mechanisms and Practice. New York: John Wiley \& Sons, 2005.

of Mechanical Engineering in Government Polytechnic College, Puducherry, India and a part time research scholar in mechanical engineering, Pondicherry University, Puducherry, India. His research interests include surface engineering, surface level metal matrix composites and thermal analysis. 